\title{
Study of the right ear advantage on gap detection tests
}

\section{Summary}

\begin{abstract}
$\mathrm{T}$ emporal resolution hearing skills are based on the minimum time necessary to segregate or solve acoustic events. This skill is fundamental for speech comprehension and can be assessed by gap detection tests. Some studies point to a right ear advantage over the left ear in temporal resolution tasks, since there is a preferential role of the left hemisphere in analyzing the temporal aspects of the acoustic stimulus. Aim: determine if there are response differences (gap detection thresholds and percentage of correct answers) between right and left ears in a gap detection test. Study: experimental. Materials and Methods: the gap detection test was applied to 100 adult individuals, after carrying out other audiologic tests in order to rule out possible hearing and/or auditory processing disorders. Results: We observed gap detection thresholds and average correct answers percentages, which were similar for both ears, regardless of which ear started the test. Conclusion: There was no ear advantage in the gap detection task.
\end{abstract}

${ }^{1}$ Doctor in Science, FMUSP, faculty member of the speech therapy course, Guarulhos University.

2 'Livre-docente' habilitation, faculty member of the speech therapy course, FMUSP.

Paper submitted to the ABORL-CCF SGP (Management Publications System) on December 27, 2006 and accepted for publication on January 29th, 2007. cod. 3570. 


\section{INTRODUCTION}

The gap detection test is a relatively simple psychoacoustic test for measuring temporal resolution..$^{1-7}$ The auditory ability for temporal resolution is the minimum time required for separating or resolving acoustic events. ${ }^{8,9}$

In trying to locate the physiological mechanism of temporal resolution, some authors have suggested that auditory nerve fibers participate significantly in the process., ${ }^{5,10,11}$ Other studies, however, have shown that processing is more central. ${ }^{12-26}$

Temporal resolution depends on the separation of different auditory stimuli; the role of the initial part of the stimulus and the coding precision of this response are crucial. ${ }^{19,24}$

Auditory cortex neurons are particularly sensitive to these initial transitory stimuli, including the beginning of periodic events, the incident modulation of other periodic signals o the acoustic events that occur naturally in vocalization. ${ }^{12}$

Primary auditory cortex neurons respond briefly and transitorily to the beginning of sounds, regardless of signal duration. These neurons are sensitive to sound frequency and the duration of its onset (attack), which contributes significantly to the signal onset short-term spectrum. Response brevity at the onset of sound is marked by the post-initial inhibitory response and by neural adaptation..$^{15}$

The precision of the first neural firing that responds to the onset of sound is proportional to the neural response latency. Phillips and Hall ${ }^{13}$ found latency as short as $0.45-1.5 \mathrm{~ms}$ for first neural firing in the auditory cortex of cats. These values are very close to those observed in the cochlear nerve and the cochlear nucleus, suggesting that temporal fidelity for transitory responses is preserved in afferent pathways until the primary auditory cortex. ${ }^{17,22}$

This degree of precision in response time supports temporal resolution at the limits of behavioral performance, a task for which the auditory cortex is important. Furthermore, such degree of precision is able to represent the duration of the phonetically important components of speech signals. ${ }^{13,16}$

The human auditory cortex is located in the temporal lobe. It is organized in a koniocortical cytoarchitecture central core (small cells in all layers in a highly granulated and myelinized area) surrounded by a less granulated cortical auditory belt. This core area is the primary auditory cortex, located in the transverse gyrus (Heschl's gyrus) on the upper surface of the temporal lobe. ${ }^{27}$

Heschl's gyrus is highly variable among individuals and between both hemispheres. It may contain one to three gyruses per hemisphere and the number of gyruses is not necessarily equal in both hemispheres. ${ }^{28}$

The primary auditory cortex is located approximately in half of the first gyrus or in half of the first gyrus and in part of the second gyrus; it covers about the central two thirds of Heschl's gyrus..$^{25,28-30}$

Many studies have demonstrated the existing asymmetry between the right and left Heschl's gyruses. The left gyrus is larger than the right gyrus; thus, the left primary auditory cortex is also larger than the right primary auditory cortex. The increased left size volume results from more gray and white matter present in this side..$^{28,31,32}$

The larger neural substrate (more neurons and more intra- and interhemispheric interconnections) in these left hemisphere anatomic structures provides the basis for better language development compared to the corresponding (smaller) areas in the right side. ${ }^{32}$

Left hemisphere speech specialization may be related to an identification of specific acoustic parameters for sound and speech discrimination. The ability to code and analyze temporal aspects within acoustic information may be related with the left hemisphere contribution to language functions. ${ }^{28}$

Numerous findings have demonstrated the preferential role of the left hemisphere in analyzing temporal aspects of acoustic stimuli; it is possible that the observed structural differences between both hemispheres define this differentiated ability. ${ }^{28,33}$

Zatorre and Belin ${ }^{33}$ investigated functional differences between the auditory cortex of the right and left hemispheres. Neuroimaging methods revealed increased activation of Heschl's gyrus in both hemispheres, although the left side responded more to temporal tasks; on the other hand, spectral changes caused more activation in the superior temporal gyrus bilaterally, but with an increased response in the right side. These differences were explained as being anatomical differences. More significant left hemisphere myelinization increases conduction speed, making this hemisphere more sensitive to rapid acoustic changes. At the same time, increased space between cortical columns and highly intrinsic connections in the left hemisphere allow integration along tonotopicallyorganized areas, impoverishing the spectral resolution. The opposite applies to the right hemisphere, in which structural patterns favor high frequency resolution at the cost of slower transmission.

Brown e Nicholls ${ }^{34}$ used a gap detection test to assess adult temporal resolution and perceptual asymmetry between ears. The acoustic stimulus was broadband noise (74 dB NPS) lasting 300ms. Four gap intervals were inserted: 2, 4, 6 and $8 \mathrm{~ms}$. The authors found faster and more accurate responses in the right ear (left hemisphere) compared to the left ear.

Sulakhe et al..$^{35}$ obtained similar results. Two types of noise (white and narrow band noise) were used. Stimulus duration was $300 \mathrm{~ms}$ and the gaps were 3,4 or $5 \mathrm{~ms}$. The authors found hemispheric asymmetry with a right ear advantage for white noise and hemispheric symmetry for 
narrow band noise. The explanation was that these differences (symmetry versus asymmetry) could be attributed to the various stimulus parameters.

Other authors, however, have found no perceptual asymmetry between right and left ears, that is, they observed no right ear advantage over the left ear in auditory temporal processing and temporal resolution tasks. ${ }^{36-38}$

The purpose of this article was to observe whether there were any response differences (gap detection thresholds and percentage of correct answers) between right and left ears in a gap detection test.

\section{MATERIAL AND METHOD}

The Research Ethics Committee for research project analysis (CAPPesq) approved this study (protocol number 113/02, 13/03/2002).

\section{Subjects}

The analysis included 100 adult subjects aged from 18 to 31 years; 50 were male (mean age 24.72 years) and 50 were female (mean age 23.77 years). The youngest male was aged 18 years and the youngest female was aged 18.16 years. The maximum age in males was 31.5 years and in females it was 31.83 years $(\mathrm{p}=0.176)$.

The sample was not divided according to righthandedness, as the general prevalence of right-handed individuals is about $90 \%$. Furthermore, $95 \%$ of right-handed and $70 \%$ of left-handed individuals have left hemispheric language specialization. ${ }^{39}$ If the sample contained individuals with right hemispheric specialization, they would not be sufficient to contaminate the results.

\section{Material and Procedures}

All participants were informed about the voluntary nature of the study, its objectives, the exams that would be applied, the absence of health risks due to the study procedures, and the dissemination of results among the science community. If there was agreement about these requirements, patients were asked to sign a free informed consent form before participating in the study.

After this agreement, the following procedures were undertaken in the entire sample: clinical history taking, pure tone audiometry, immitance testing and the digital dichotic test (as basic screening of auditory processing ${ }^{40}$ ). All subjects had auditory thresholds below 20 dBNA at all of the tested frequencies $(0.25$ to $8 \mathrm{KHz}),{ }^{41}$ a type $\mathrm{A}$ tympanometric curve and ipsi- and contralateral acoustic reflexes, and correct answers equal to or over $95 \%$ in each ear in the digital dichotic test. ${ }^{44}$

The GIN test, developed by Musiek in 2003, ${ }^{38,45}$ was then applied. An Interacoustic AC 40 audiometer, coupled to a Sony CD player, in an acoustic booth, at a $50 \mathrm{~dB}$ NS intensity (according to mean auditory thresholds at 500, 1000 and $2000 \mathrm{~Hz}$ in each ear) was used for the test. A monaural presentation condition was used throughout.

The GIN test is composed of various 6-second white noise segments, each with 0 to 3 silence gaps each. Noise segments are separated from each other by a 5-second silent interval (interval between stimuli) and gap duration is $2,3,4,5,6,8,10,12,15$ and $20 \mathrm{~ms}$. The occurrence of gap duration and location within noise segments is pseudo-randomized. There are ten practice items that precede the beginning of test items. Each gap of different duration appears six times in each list. The test is composed of four lists. ${ }^{38}$

Each ear is assessed separately twice (two lists for each ear). Two measurements are made for each list: gap detection threshold (smallest gap perceived by patient in at least $50 \%$ of presentations - three times - as each gap appears six times in each list), and the percentage of correct answer in each list (the total number of gaps detected).

Subjects were divided as follows to discard possible influences from the test ear: the GIN was done first in the right ear in 50\% of subjects ( 25 male subjects and 25 female subjects), and the GIN was done first in the left ear in the other $50 \%$ of subjects ( 25 male subjects and 25 female subjects).

The ANOVA test was used for the statistical analysis. The significance level was 0.05 .

\section{RESULTS}

Right and left ear results of the 100 subjects are presented regardless of the first ear that was tested. As each ear was assessed twice, 400 samples were collected, 200 from right ears and 200 from left ears (Figures 1 A and $1 \mathrm{~B})$.

Figures $1 \mathrm{~A}$ and $1 \mathrm{~B}$ show that gap detection thresholds were similar in both ears. Furthermore, most of the thresholds were about $4 \mathrm{~ms}$ for both ears.

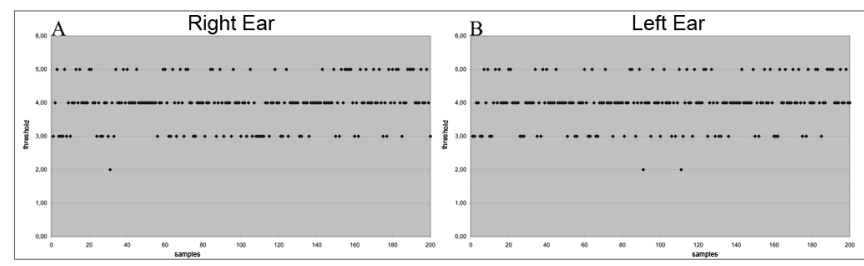

Figure 1. Gap detection thresholds in 400 samples (in $\mathrm{ms}$ ) - (A) right ear $(B)$ left ear.

Table 1. Mean, standard deviation and the $p$-value for gap-detection thresholds in a comparison between right and left ears.

\begin{tabular}{ccccc}
\hline Ear & $\mathrm{n}$ & Mean $(\mathrm{ms})$ & Standard deviation & $\mathrm{p}$ \\
\hline RE & 200 & 3,985 & 0,683 & 1,0000 \\
LE & 200 & 3,985 & 0,669 & \\
\hline
\end{tabular}


These results are made more evident by the statistical analysis (ANOVA) (Table 1).

A similar pattern was observed in the percentage of correct answers, in which right and left ear results were similar (Figure $2 \mathrm{~A}$ and 2B; Table 2).

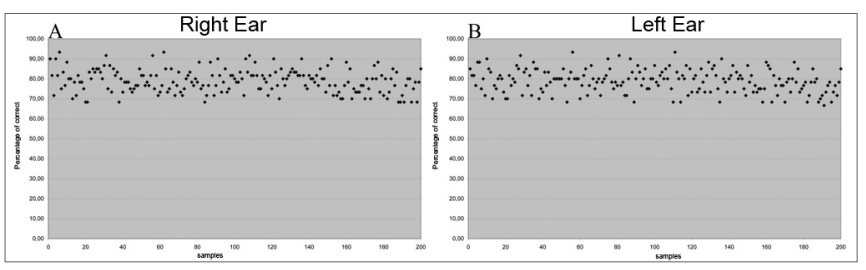

Figure 2. Percentage of correct answers in 400 samples (in \%) - (A) right ear $(\mathrm{B})$ left ear.

Table 2. Mean, standard deviation and the $p$-value for the percentage of right answers in a comparison between right and left ears.

\begin{tabular}{ccccc}
\hline Ear & $\mathrm{n}$ & Mean (\%) & Standard deviation & $\mathrm{p}$ \\
\hline RE & 200 & 78.922 & 5.810 & 0.8650 \\
LE & 200 & 78.872 & 5.836 & \\
\hline
\end{tabular}

Figure 3 shows the correct answers in each ear for gap intervals of 2 to $8 \mathrm{~ms}$. The percentage of correct answers for these gap intervals are similar in both ears; there was no higher prevalence of correct answers in any one ear. The percentage of correct answers for a $2 \mathrm{~ms}$ gap interval was close to $4 \%$. This percentage was around $20 \%$ for $3 \mathrm{~ms}$. Correct answers improved considerably (around $70 \%$ ) for a $4 \mathrm{~ms}$ gap interval. The percentage of correct answers was higher than 90\% for 5 and $6 \mathrm{~ms}$ gap intervals, reaching $100 \%$ for $8 \mathrm{~ms}$ or more gap intervals.

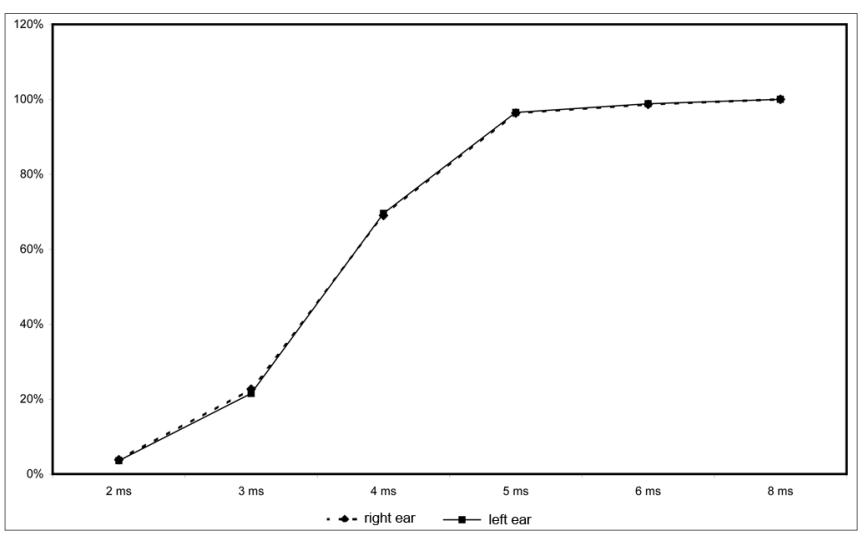

Figure 3. Percentage of correct answers per gap intervals in each ear (in \%).

\section{DISCUSSION}

These results reveal that no ear had any advantage relative to the other in all of the tests (gap thresholds, percentage of correct answers or percentage of correct answers per gap interval).
These results differ from those in various other published papers, which have shown an advantage for the right ear (left hemisphere) in temporal resolution tasks. ${ }^{34,35}$ Our results, however, agree with those of Efron et al., ${ }^{36}$ Baker et al., ${ }^{37}$ and Musiek et al., ${ }^{38}$ in which no perceptual asymmetry was found between ears in gap detection procedures. Baran and Musiek ${ }^{46}$ have stated that monochotic tests are useful for detecting alteration in auditory pathways but not for locating these changes, as ipsi- and contralateral pathways participate in this process, which results in similar right and left ear performance.

Many authors have suggested that the left hemisphere has a preferential role in analyzing temporal aspects of acoustic stimuli. ${ }^{28,33}$

The currents study found no right or left ear advantage (or no hemispheric advantage) in gap detection tasks. There are, however, a few points that should be emphasized.

Brown and Nicholls ${ }^{34}$ and Sulakhe et al. ${ }^{35}$ have reported a right ear advantage over the left ear, while Efron et al., ${ }^{36}$ Baker et al., ${ }^{37}$ and Musiek et al. ${ }^{38}$ found no asymmetry between ears.

Brown and Nicholls ${ }^{34}$ and Sulakhe et al. ${ }^{35}$ used the reaction time to the presence of gaps for their analysis. Further more, the former study evaluated the rate of false results, while the latter assessed the percentage of correct answers. The reaction time was not tested in the current study and in Efron et al.' ${ }^{36}$ and Baker et al.'s ${ }^{37}$ studies, which may in part explain the difference between results. If the left hemisphere has a larger neural substrate, ${ }^{32}$ a more rapid right ear temporal resolution might be expected, as found by the abovementioned authors.

The type of response in these studies was a "yes or no" procedure, while Efron et al. ${ }^{36}$ and Baker et al. ${ }^{37}$ used the 2AFC (two-alternative forced-choice) procedure, as well as different analysis parameters, namely the psychometric function (percentage of correct answers per gap interval), similar to the current study.

Gap thresholds and the percentage of correct answers might possibly mask the right ear advantage, which may become even more evident in the reaction time analysis.

In summary, different parameters used in these studies, including this one, may explain these contradictory findings on the perceptual asymmetry of temporal resolution between ears. This does not mean, that there is no left hemisphere advantage for such tasks, but rather that certain procedures cannot assess this difference. It should also be borne in mind that ipsi- and contralateral pathways are activated in monochotic assessments, which precludes advantages for any ear.

Furthermore, other cortical areas - besides the primary auditory cortex - may participate in auditory processing of rapid stimuli; further conclusions are not possible without more detailed investigation about this theme..$^{47,48}$ 


\section{CONCLUSION}

There was no difference in gap-detection thresholds and the percentage of correct answers between right and left ears in the gap detection test (GIN - Gaps In Noise).

\section{REFERENCES}

1. Phillips DP, Taylor TL, Hall SE, Carr MM, Mossop JE. Detection of silent intervals between noises activating different perceptual channels: some properties of "central" auditory gap detection. J Ac Soc Am 1997;101(6):3694-705.

2. Schulte-Körne G, Deimel W, Bartling J, Remschmidt H. Role of auditory temporal processing for reading and spelling disability. Perc Motor Sk 1998;86:1043-7.

3. Phillips DP, Hall SE, Harrington IA, Taylor TL. "Central" auditory gap detection: a spatial case. J Acoust S Am1998;103(4):2064-8.

4. Wiegrebe L, Krumbholz K. Temporal resolution and temporal masking properties of transient stimuli: data and an auditory model. J Acoust S Am1999;105(5):2746-56.

5. He N, Horwitz AR, Dubno JR, Mills JH. Psychometric functions for gap detection in noise measured from young and aged subjects. J Acoust S Am1999 106(2):966-78.

6. Florentine M, Buus S, Geng W. Psychometric functions for gap detection in a yes-no procedure. J Acoust S Am1999;106(6):351220.

7. Oxenham AJ. Influence of spatial and temporal coding on auditory gap detection. J Acoust S Am2000;107(4):2215-23.

8. Irwin RJ, Ball AKR, Kay N, Stillman JA, Rosser J. The development of auditory temporal acuity in children. Child Dev 1985;56(3):61420.

9. Shinn JB. Temporal processing: the basics. Hear J 2003;56(7):52.

10. Giraudi-Perry DM, Salvi RJ, Henderson D. Gap detection in hearingimpaired chinchillas. J Acoust S Am 1982;72(5):1387-93.

11. Snell KB, Hu H. The effect of temporal placement on gap detectability. J Acoust S Am 1999;106(6):3571-7.

12. Phillips DP. Effect of tone-pulse rise time on rate-level functions of cat auditory cortex neurons: excitatory and inhibitory processes shaping responses to tone onset. J Neurophysiol 1988;59(5):152439.

13. Phillips DP, Hall SE. Response timing constraints on the cortical representation of sound time structure. J Acoust S Am 1990;88(3):1403-11.

14. Phillips DP, Sark S. A. Separate mechanisms control spike numbers and inter-spike intervals in transient responses of cat auditory cortex neurons. Hear Res 199;53:17-27.

15. Phillips DP. (1993a) Neural representation of stimulus times in the primary auditory cortex. An NY Acad Sci 1993;682:104-18.

16. Phillips DP. (1993b) Representation of acoustic events in the primary auditory cortex. J Exp Psychol 1993;19(1):203-16.

17. Phillips DP. Central auditory processing: a view from auditory neuroscience. Am J Otol 1995;16(3):338-52.

18. Eggermont JJ. Firing rate and firing synchrony distinguish dynamic from steady state sound. Neuroreport 1997;8(12):2709-13.

19. Horikawa J, Hosokawa Y, Nasu M, Taniguchi I. Optical study of spatiotemporal inhibition evoked by two-tone sequences in the guinea pi auditory cortex. J Comp Physiol 1997;181:677-84.

20. Kilgard MP, Merzenich MM. Distributed representation of spectral and temporal information in rat primary auditory cortex. Hear Res 1999;134:16-28.

21. Eggermont JJ. Neural responses in primary auditory cortex mimic psychophysical, across-frequency-channel, gap-detection thresholds. J Neurophysiol 2000;84:1453-63.

22. Heil P. Representation of sound onsets in the auditory system. Audiol Neurootol 2001;6:167-72.
23. Rupp A, Gutschalk A, Hack S, Scherg M. Temporal resolution of the human primary auditory cortex in gap detection. Neuroreport 2002;13(17):2203-7.

24. Sugimoto S, Hosokawa Y, Horikawa J, Nasu M, Taniguchi I. Spatial focusing of neuronal responses induced by asynchronous twotone stimuli in the guinea pig auditory cortex. Cortex Cerebral 2002;12(5):506-14

25. Hall DA, Hart HC, Johnsrude IS. Relationships between human auditory cortical structure and function. Audiol Neurootol 2003. 8(1):1-18.

26. DeWeese MR, Wehr M, Zador AM. Binary spiking in auditory cortex. J Neurosci 2003;23(21):7940-9.

27. Hackett TA, Preuss TM, Kaas JH. Architectonic identification of the core region in auditory cortex of macaques, chimpanzees, and humans. J Comp Neurol 2001;441:197-222.

28. Penhune VB, Zatorre RJ, MacDonald JD, Evans AC. Interhemispheric anatomical differences in human primary auditory cortex: probabilistic mapping and volume measurement from magnetic resonance scans. Cereb Cortex 1996;6(5):661-72.

29. Rupp A, Hack S, Gutschalk A, Schneider P, Picton TW, Stippich C, Scherg M. Fast temporal interactions in human auditory cortex. Neuroreport 2000;11(17):3731-6.

30. Kass JH, Hackett TA. Subdivisions of auditory cortex and processing streams in primates. Proc Nat Acad Sci USA 2000;97(22):11793-9.

31. Rubens AB. Anatomical asymmetries of human cerebral cortex. Em: Harnad S, Doty RW, Goldstein L, Jaynes J, Krauthamer G. Lateralization in the nervous system. New York: Academic Press; 1977. p. 503-16.

32. Musiek FE, Reeves AG. Asymmetries of the auditory areas of the cerebrum. J Am Acad Audiol 1990;1:240-5.

33. Zatorre RJ, Belin P. Spectral and temporal processing in human auditory cortex. Cereb Cortex 2001;11(10):946-53.

34. Brown S, Nicholls MER. Hemispheric asymmetries for the temporal resolution of brief auditory stimuli. Percep Psychophys 1997;59(3):442-7.

35. Sulakhe N, Elias LJ, Lejbak L. Hemispheric asymmetries for gap detection depend on noise type. Brain Cogn 2003. 53(2):372-5.

36. Efron R, Yund EW, Nichols D, Crandall PH. An ear asymmetry for gap detection following anterior temporal lobectomy. Neuropsychol 1985. 23(1):43-50.

37. Baker RJ, Rosen S, Godrich A. No right ear advantage in gap detection. Speech, Hearing and Language (UCL work in progress) 2000. 12:57-69.

38. Musiek FE, Shinn JB, Jirsa R, Bamiou DE, Baran JA et al. GIN (Gaps-In-Noise) Test Performance in Subjects with Confirmed Central Auditory Nervous System Involvement. Ear Hear 2005;26 (6):608-18.

39. Previc FH. A general theory concerning the prenatal origins of cerebral lateralization in humans. Psychol Rev 1991;98(3):299-334.

40. Jerger J, Musiek FE. Report of the consensus conference in the diagnosis of auditory processing disorders in school-aged children. J Am Acad Audiol 2000;11(9):467-74.

41. Yantis PA. Avaliação dos limiares auditivos por via aérea. Em:Katz J. Tratado de Audiologia Clínica. São Paulo: Ed. Manole; 1999. Capítulo 7.

42. Hall JW, Chandler D. Timpanometria na audiologia clínica. Em: Katz J. Tratado de Audiologia Clínica. São Paulo: Ed. Manole; 1999. Capítulo 20.

43. Northen JL, Gabbard SA. Reflexo acústico. Em: Katz J. Tratado de Audiologia Clínica. São Paulo: Ed. Manole; 1999. Capítulo 21.

44. Santos MFC. Processamento auditivo central: teste dicótico de dígitos em crianças e adultos normais [tese]. São Paulo:Escola Paulista de Medicina (Unifesp); 1998.

45. Musiek FE, Zaidan EP, Baran JA, Shinn JB, Jirsa RE. Assessing temporal processes in adults with LD: the GIN test. Em: Convention 
of American Academy of Audiology. 2004 March - April, Salt Lake City. Annals... Salt Lake City: AAA, p. 203, 2004.

46. Baran J, Musiek FE. Behavioral Assessment of the Central Auditory System. Em: Musiek FE, Rintelmann W (eds.) Contemporary Perspectives on Hearing Assessment. Boston: Allyn \& Bacon; 1999. Capítulo 13.
47. Temple E, Poldrack RA, Protopapas A, Nagarajan S, Salz T, Tallal P, Merzenich MM. Disruption of the neural response to rapid acoustic stimuli in dyslexia: evidence from functional MRI. Proc Nat Acad Sci USA 2000;97(25):13907-12.

48. Buonomano DV, Karmarkar UR. How do we tell time? The Neuroscientist 2002;8(1):42-51. 